\title{
The Abstract Reality of the "Hardcore Continuum"
}

\author{
MARK FISHER \\ GOLDSMITHS, UNIVERSITY OF LONDON (UK)
}

from

the

floor

The debate around whether the "hardcore continuum" (henceforth HCC) - see the previous article by Jeremy Gilbert for the background - should be classified as a "theory" or a "fact" has raised important issues about the relationship between music criticism and theory. What I propose to do here is offer a brief defence of both the HCC and of theory. Put very schematically, the recent objections to the concept of the "hardcore continuum" culture seem to take two basic forms: (1) there never was such a thing as the hardcore continuum in the first place; and (2) there was such a thing as the hardcore continuum, but it is no longer relevant to today's dance music.

Ironically, given the professed anti-theoretical intentions of many of the objectors to the HCC, both these objections cannot be resolved by appeal to facts, since both very quickly raise deeply philosophical questions - questions that, as it happens, are at the centre of intense current debates surrounding speculative realism and objectoriented philosophy. The reason that appeals to a supposedly direct, pre-theoretical "experience" must fail is that both the objections turn on the question of what a "thing" is, a question, which to say the very least, has philosophical implications. Empiricism, even in a far more sophisticated form than the so-called "buffoon empiricism" espoused by Dan Hancox at the "Hardcore Continuum" symposium at the University of East London on 29th April 2009 precisely ran aground because it could give no convincing answer to this question. Indeed, it is one of the problems on which British empiricism ran aground: far from being a flux of primary qualities and raw sensations that is cut up into objects only after the fact, the very "experience" that empiricists privilege is already impregnated with "thinghood". Once you subtract generalised concepts not given in immediate sensations, you don't end up with the concrete certainties that buffoon empiricism appeals to. Instead, as Berkeley ingeniously demonstrated, the material world itself disappears (there is no sensation that corresponds to "matter"; it has to be inferred as the cause of those sensations). David Hume found that the self and causality would also disintegrate, since they are not experienced as sensations either. Thus, the appeal to direct sensation would not end up in a lumpen commonsense, but in a psychosis. The first objection must give an account of what a "thing" is, without assuming that such a definition is already given to us by unreflective experience.

The hardcore continuum was something that Simon Reynolds identified in the 1990s, but named retrospectively. In his presentation at FACT in Liverpool, ${ }^{1}$ Reynolds used what would come to be a controversial analogy, arguing that the HCC is a "fact" in the same way that Australia - the land mass, with its flora and fauna, as opposed to the politically-constituted "nation" - is. I want to argue here that Reynolds' tactical retreat from theory is a mistake. However, I wouldn't want to go as 
far as Alex Williams who argues that the hardcore continuum is a purely theoretical entity. Williams ingeniously claims that the HCC

is real, but only as a theory. In other words, the theory exists and has certain effects - how it influences other forms of production, how it adds to our own experiences of music. It is certainly related to a reality external to itself (a set of musics, clubs, people) but its role is not passive, but active. The act of naming is not a naturalistic or scientific act of description, but a creative act itself, an invention, not a discovery.

Part of the problem with Williams' "hyperstitional" account of the HCC is the fact that it has hardly fed back into production at all; its main impact has been upon the consumption and theorisation of music. I would argue that the name "hardcore continuum" (and the theorisation and discussion of the HCC) is irrelevant to the reality that the name designates. In that sense, the analogy with Australia-the-landmass holds; the landmass retains the same features irrespective of the name that it is given. But there are obvious limits to the Australia analogy - because the reality of the hardcore continuum is not of the order of a physical fact, but of an abstract entity. The notion of an abstract-real materiality may cause commonsense to recoil, yet a moment's reflection makes us realise that, not only that abstract entities are real, but that there is nothing more real than them. Unless we posit abstract entities, what sense can we make of the credit crunch and the recession we are currently living through? Then there is the Lacanian big Other, the collective fiction which structures and makes consistent social reality itself. For me, the hardcore continuum is rather like capital: it cannot be experienced as such, but it has clearly identifiable effects. It is not a theoretical entity, but it can only be encountered via some kind of theoretical reflection. The same questions of agency come up when thinking about the continuum as thinking about capital. Part of what was interesting about the concept of the HCC was that "it" rather than individual artists seemed to be the creative force in generating music. The hardcore continuum was an exuberant effacement of the author in a collective circuit which included producers, DJs and dancers, but which displayed its own cybernetic intelligence not reducible to the intentions and objectives of individual human agents. The actions of producers, DJs and dancers were both constrained and enabled by the vicissitudes of the continuum; they could not enforce a change in style by fiat. That is why appeals to biography establish nothing - the fact that individuals were also involved in producing other kinds of music alongside their HCC-related work tells us only that pseudonyms designate real differences. The defacialised names that producers and DJs adopt are not neutral tags for an underlying biological-biographical being; rather they indicate really different entities with their own traits. Take the example of Goldie: when he started to believe that it was he the biographical-biological individual - as opposed to the fictive-real entities "Rufige Kru" or "Metalheadz" - that was responsible for his productions, they became grossly self-indulgent follies.

Part of the reason that it is important to reflect on the hardcore continuum is that it was an example of a culture in which, to use archaic and perhaps misleading terms, "tradition" and the "individual talent" could interact. There was a system in place tight enough to ensure a kind of evolving consistency, but loose enough to enable innovation. Here was a culture in which there was "interactivity" and "participation" but it happened at the right speed - the circuit in place didn't flatten out into immediate access for everyone. Unlike Web 2.0, the time of the HCC was still a punctual time. It was still the time of dub plates, clubs and record releases, not the dissolute and dis- 
tributed Web 2.0 time of leaked mp3 downloads, play-anytime webcasts and instantaneous comment.

The second objection raises questions which connect with broader debates about postmodernism and hauntology. This decade's dance music is held to have moved beyond critical models established in response to the music of the 1990s, and the disputes here bring into play a certain generational antagonism, the devotees of this decade's dance music arguing that those who continue to talk about the HCC are out-of-touch nostalgics. But there is something unusual about this generational antagonism. The complaint of the older generation here is not the familiar one that new music is incomprehensible. On the contrary - the problem is that the music being produced this decade is all too comprehensible. It arises from a sense of disappointment that we are still in the same sonic phase space established a decade and a half ago. The period from the 1960s to the 1990s in popular music was marked by future shock, by the arrival of new forms which were continually obsolescing pre-existing critical models, and which would have been sonically unimaginable only a few years - or even a few months - previously. The reason that the hardcore continuum is particularly significant is that, as Simon Reynolds puts it, ${ }^{3}$ it constitutes nothing less than

modernism's last stand, or unexpected comeback, long after the ideals of modernism had been abandoned, eroded, questioned, everywhere else (including in pop music).... Amazingly it was able to evade the blight of postmodernity (irony, referentiality, citational aesthetics) even as it embraced and explored to the hilt the potential of what would on the surface seem to be the ultimate postmodern sound-machine, the sampler.

The issue of whether funky house or wonky have the same modernist velocity as jungle, speed garage and 2-step is far more significant than the - still contentious and interesting - question of whether they can still be classified as belonging to the hardcore continuum. It is not as if either funky or wonky have fully succumbed to the conditions of nostalgia and pastiche which are elsewhere completely dominant in postmodern culture. And there is no doubt that these scenes produce "good records". The problem, though, can be grasped by a little time travel thought experiment. Imagine if it were possible to slip a wonky or a funky house track into a jungle set in 1993. Likely as not, there would have been a sense of incongruity, but there wouldn't be future shock. But jungle would have provoked a sense of future shock if it were played to ravers in 1990, never mind if it were played in 1977 (the same difference in time between 1993 and now). The deceleration implied by this thought experiment produces what I have called "past shock". Drawing upon the work of Reza Negarestani and Felix Guattari, Alex Williams has convincingly theorised wonky as "a kind of process, rather than a fixed endpoint, a liquidation rather than a fusion, a process which occurs to preexisting genres rather than being a genre itself." Like the hauntological music of Ghost Box or Burial, but functioning via decay instead of spectrality, wonky emerges in this theorisation as an alternative to the postmodern "nostalgia mode" which nevertheless grants that a certain future-oriented velocity has been arrested.

Shadowing both objections is a hostility to theory itself. Theory is cast in the role of a curmudgeon, preventing unreflective enjoyment. But no such enjoyment has ever been possible, and the role of criticism - especially a criticism formed and informed by the pulp modernism of something like the HCC - is evidently not simply to act as scenester cheerleading for whatever happens to be produced now. Moreover, theory's role 
is not opposed to that of dancing; in many respects, in fact, theory stands in the same relation to music as does dance. Its function is to complicate and estrange music, not to simply "respond" or "assess" it, a particularly important role at this time, when so much writing about music is either breathless PR or dry consumer guides.

\section{Author Biography}

Mark Fisher is a writer and theorist based in Suffolk, UK. He is a Visiting Fellow at the Centre for Cultural Studies at Goldsmiths, University of London and he teaches Philosophy at the City Literary Institute in London. His book Capitalist Realism will be published by Zer0 books in November 2009. He has edited The Resistible Demise Of Michael Jackson, a collection of essays on Jackson by academics and music journalists, which will also be published by Zer0 in November 2009. His weblog can be found at http://k-punk.abstractdynamics.org.

\section{Notes}

1 <http://energyflashbysimonreynolds.blogspot.com/2009/02/hardcore-continuum-ortheory-and-its.html $>$ (accessed 20 September 2009).

2 <http://splinteringboneashes.blogspot.com/2009/04/invention-or-discovery-or-whenis-genre.html> (accessed 20 September 2009).

3 <http://energyflashbysimonreynolds.blogspot.com/2009/05/nuum-and-itsdiscontents-4-party.html> (accessed 20 September 2009). 